\title{
LA EXPERIENCIA DE LA DELINCUENCIA EN DOS ABORDAJES ETNOGRÁFICOS ALTERNATIVOS
}

\author{
Joaquín Santiago Gomez
}

\begin{abstract}
RESUMO
En este artículo reseñaré críticamente tres etnografías que han abordado la experiencia de la delincuencia en las sociedades contemporáneas. Lo haré señalando el modo en que han definido su objeto y realizado su trabajo, como es de rigor, pero sobre todo conduciendo la discusión a lo que entiendo dos formas radicalmente otras de construir el campo. Precisamente, atender al lugar diferencial que ocupa el "hecho delictivo" en estos trabajos antropológicos llevará a situar en líneas de indagación alternativas, por un lado, el reciente trabajo realizado en Argentina por Daniel Míguez y, por otro, dos etnografías brasileñas ancladas en la ciudad de Rio de Janeiro - entre las que encontramos una clara continuidad -, los trabajos de Alba Zaluar y Marcos Alvito. En un último apartado, me detendré a señalar la fructífera relación, no reconocida explicitamente en las etnografías que reseñamos, que esta línea de trabajo desarrollada en Brasil puede tener con los trabajos de Michel Foucault (esa relación es más patente en otros autores, como Michel Misse, cuya producción también podría ser incluida en esta perspectiva). De este modo, pretendo llamar la atención sobre aquellos abordajes que si bien pueden ofrecer aportes valiosos sobre tal o cual cuestión puntual, permanecen ciegos a los mismos fenómenos que la criminología convencional ignora dado que comparten con ésta la construcción de un campo de estudio centrado en la "delincuencia".
\end{abstract}

PALAVRAS-CHAVE: delincuencia; etnografia; criminología; construcción; Rio de Janeiro.

\section{INTRODUÇÃO: DELITO Y CULTURA: LOS CÓDIGOS DE LA ILEGALIDAD EN LA JUVENTUD MARGINAL URBANA.}

A lo largo de las páginas de Delito y cultura: los códigos de la ilegalidad en la juventud marginal urbana, Daniel Míguez (2008), doctor en Antropología por la Universidad de Ámsterdam, presenta los recorridos y las conclusiones alcanzadas tras cerca de diez años de investigación en el tema. Se trata de un libro en el que se articulan diferentes dimensiones y modos de abordaje al "problema del delito": su cuantificación, su trato institucional, sus principios explicativos, su evolución y las variantes culturales (o subcultura) que lo acompañan y, hasta cierto punto, le dan forma. La matriz conceptual con que se articulará toda esta indagación es la de la integración social en general y la de los sectores subalternos en particular. Serán las representaciones y prácticas de los jóvenes en conflicto con la ley las que conformarán el objeto privilegiado de este estudio. En este sentido, la hipótesis a demostrar por el autor será la consistencia de estas representaciones y prácticas en un sistema subcultural del delito juvenil, que se define endogámicamente por la transgresión a la norma legal y un particular uso de la violencia física. Asimismo, el autor defenderá la validez empírica de un hallazgo: una transformación en esta subcultura que va tomando fuerza a mediados de la década de los 1990 y conlleva una menor regulación de la violencia (tanto en términos subculturales como en la intervención estatal). Esta mutación sería aquello que está detrás del malestar social en torno la cuestión de la seguridad urbana que se expresa in crescendo hace una década en la Argentina.

Será el objeto de un segundo capítulo central desde el punto de vista de su argumentación conceptual, enfocar la sociogénesis de esta subcultura delictiva, como pauta de sociabilidad específica dentro del difícil proceso de integración social que deben atravesar todos los miembros de una sociedad. El análisis puntúa en que nuestras sociedades, en tanto que sociedades complejas, generan diferencias sectoriales que también alcanzan a las concepciones de la niñez y la adolescencia, lo que conlleva a diferentes pautas de sociabilidad. Ante lo que considera una falta de investigaciones empíricas para contrastar los 
datos de su investigación, Míguez (idem), recurre al modelo ideal elaborado por Norbert Elias para caracterizar la forma convencional de sociabilidad. En este esquema una integración exitosa a la sociedad moderna supone la generación de un mecanismo de "autocoacción" (corporal, emocional y del uso de la fuerza) útil para manejarse en redes sociales crecientemente abstractas y generalizadas donde las finalidades expresivas priman sobre las instrumentales. En el caso de los jóvenes cuyas prácticas y representaciones son objeto de este estudio, la socialización transcurre en el tránsito entre una serie de instituciones - el hogar, la calle y el instituto de menores - que no logran contenerlos ni protegerlos de la exposición a vínculos instrumentales. No se trata, para el autor, de un fenómeno que pueda vincularse linealmente a la posición socioeconómica de la familia sino, continuando la conceptualización eliasiana, a la "funcionalidad o redundancia" que representa la progenie para los progenitores. Los datos obtenidos en las entrevistas muestran que son diferentes configuraciones las que llevan a modelos convivenciales alternativos y no exclusivamente un modelo familiar (como el monoparental). Estas formas alternativas llevan a estructurar una subjetividad individual - donde tiene muy poca relevancia la autocoacción - que luego se expresaría en la subcultura del delito juvenil. Así las cosas, Míguez (idem), a través de los datos recogidos en sus entrevistas, considera que estos modelos alternativos no son naturalizados en el interior del sector social en el que surgen, y esto por dos razones: el conflicto que producen con el sistema legal y la tensión que generan con el modelo vincular convencional que, si bien su realización es prácticamente imposible, continuaría siendo el ideal para estos sectores.

En suma, los jóvenes socializados en modelos alternativos incorporarían pautas donde la expresión emocional y la resolución violenta de conflictos no están desnaturalizadas. Sin embargo, argumentará, la constitución de la subcultura delictiva se da - como una forma de ajuste - en un espacio intermedio entre estos valores alternativos y los valores convencionales. Esto podrá advertirse en las complejas regulaciones de la violencia que el autor logra conceptualizar como un juego de diferencias interpretativas entre violencia emocional, ritualizada e instrumental.
Finalmente, Míguez (idem) realiza dos inflexiones al interior del modelo eliasiano. Para escapar a las posibles resonancias de este planteo con aquellos de la "cultura de la pobreza", rescata el creciente rol que posee la intervención voluntaria y consciente en la evolución del proceso de "modernización" tal y como es descrito por Elias (1994a; 1994b), poniendo de relieve la influencia de las agencias institucionales (y políticas de Estado) en este proceso. Además, para evitar una visión aislada de lo que el autor llama "subcultura" resalta el carácter creativo de su proceso de configuración a la vez que su imbricación, como fenómeno necesario, en los procesos generales señalando que su constitución ocurre en el hiato entre la estructuración subjetiva convencional y normativa y las posibilidades que la estructura social habilita a estos sectores sociales.

En otro capítulo, el más centrado en el análisis de los datos producidos en su trabajo de campo, el autor se propone describir las reglas, códigos y lógicas para entender el "núcleo de la subcultura del delito" partiendo de la existencia de un "orden social que estructura el mundo del delito". Se dedica, entonces, a describir un sistema taxonómico que es utilizado por los actores para dirimir significados acerca de pertenencias, estatus moral y jerarquía profesional tanto en las confrontaciones físicas como verbales. Aquí pone en evidencia un uso de la violencia altamente ritualizado y por eso sujeto a la interpretación de acuerdo a normas morales y de jerarquía. Sin embargo, también es en este proceso de reconstrucción de un sistema de representaciones y prácticas donde comienza a evidenciar indicadores de transformaciones en esta subcultura del delito. Estos cambios, cuya plausibilidad se da en la superposición de indicios de distintas fuentes, parecen señalar la preponderancia de un uso cada vez más instrumental de la violencia (incluso al interior de los miembros de la subcultura) y un debilitamiento de las jerarquías y los espacios de relevancia social que habilitaba esta institucionalidad alternativa.

Recién llegado a este punto Míguez (idem), considera que la consistencia de estas reglas subculturales debe ser colocada al interior de las redes de reciprocidad que tejen los delincuentes con sus vecinos, con las fuerzas de seguridad y con miembros de partidos políticos. Sin embargo, tanto el enfoque de las formas de organización de 
la delincuencia en su actividad extramuros (en "bandas" y en territorios), como de las relaciones de vecindad son realizados acudiendo a investigaciones de otros autores (Alba Zaluar (1994), Claudia Fonseca (2004), Nathalie Puex (2004) y Marcelo Saín (2004)), o a datos que él mismo reconoce como tangenciales. Será sólo el análisis de las relaciones "intramuros" ("ranchadas" en prisiones e institutos de menores) aquel apoyado en su propia producción de datos. Si bien esta producción se basa en un trabajo de casos reconstruidos exclusivamente a través de entrevistas (dado que no cuenta con trabajo de campo en prisiones), aporta elementos empíricos originales. Señala el modo en que la tensión entre reciprocidad positiva y negativa se vuelca hacia esta última en un proceso de faccionalización de los grupos en relación a un cambio en la reciprocidad con miembros de las fuerzas de seguridad y de partidos políticos que participan de las tramas del delito, signando el cambio por la capilarización de la corrupción.

En los últimos capítulos el autor se dedica a analizar dos manifestaciones públicas de esta subcultura: la canonización de delincuentes y la cumbia villera. Más allá de las discusiones puntuales que abren cada uno de estos campos: sobre la religiosidad popular y sobre la cuestión de la hegemonía en las expresiones culturales populares, y en la cumbia villera en particular (asuntos que fueron tratados en Míguez y Semán (2006)), el aporte a la línea central de la investigación está dado por lo que el autor llama "reiteración intercontextual" de aquel orden social descrito en los dos capítulos que los anteceden. Al mismo tiempo, resalta en este punto la capacidad de esta subcultura de adquirir un nivel público y obtener mayor grado de legitimidad social dentro del estrato social al que pertenece, aunque no sin generar fuertes tensiones tanto en el propio sector social de origen, como con la cultura convencional.

Me parece importante señalar que este estudio es enfático al rechazar la validez de cualquier lectura hecha en términos de contrahegemonía sobre estas expresiones, al tiempo que confirma lo que considera una ambigüedad típica de las culturas "transgresoras" en términos de las aspiraciones de consumo de acuerdo a la cultura convencional e, incluso, a participar de las instituciones hegemónicas. Importante, afirmé, porque considero que el modo en que se pretende saldar esta discusión sobre la dimensión política es sintomática de un enfoque que deja fuera de foco la articulación de prácticas delictivas con prácticas cotidianas $\mathrm{y}$, así, toda vinculación con una "cultura popular" (más adelante volveremos sobre este concepto). En este punto, Míguez (2008) minimiza la influencia que el recorte analítico sobre una subcultura delictiva o transgresora (aún con la reelaboración de este abordaje que permiten los Estudios Culturales de la Universidad de Birmingham) puede tener para con la complejidad de ciertos fenómenos empíricos.

En las conclusiones, el autor cierra el texto dejando una serie de interrogantes sobre la influencia de las acciones del Estado sobre esta problemática social que es el delito juvenil. Cuestionando una visión simplista que pudiera ver en la reforma legal de 2007 - por la que se adecúa la normativa local a la Convención Internacional de los Derechos del Niño - una solución a los dilemas de las políticas sobre niñez y adolescencia, apunta a la heterogeneidad de la estructura del Estado y el peso específico de las variadas culturas institucionales (aún muy poco estudiadas) que, en definitiva, guían las acciones concretas del sistema de minoridad más allá de la adscripción ideológica de los actores a un paradigma garantista o proteccionista. Sin embargo, el problema que considera de mayor profundidad es el de un posible límite que alcanza a las propias ciencias humanas. Dado que evitar el disciplinamiento no es lo mismo que garantizar la integración social, el autor deja planteado el interrogante acerca de: “Cómo se le restituye el capital cultural, social, simbólico, etc., a un juvenil que no ha podido constituir desde su infancia la estructura cognitiva, actitudinal y afectiva necesaria para participar de las instituciones integradoras de una sociedad?" (idem, p. 247).

De todos modos, creemos que al cerrar un libro de abordaje multidimensional con esta pregunta, el autor, no hace sino retrotraer la problemática al nivel del individuo. Con ello tampoco hace justicia respecto del otro diagnóstico mantenido en este estudio acerca del agravamiento de los procesos sociales (económicos, políticos y culturales) que acrecientan la masa de jóvenes expuestos a las lógicas instrumentales producidas en la reciprocidad entre fuerzas de seguridad y delincuencia. El viejo y conocido dilema, señalado 
en el clásico Visiones del control social de Cohen (1988), entre asistencia individual y cambio social, nos acecha a cada paso. Aunque, tal vez, esto se deba a que difícilmente sea posible pensar el segundo elemento de la tensión (el cambio social) sin el interrogante por las relaciones de fuerza que componen el campo donde los sujetos conducen sus prácticas. $\mathrm{Y}$, pese a los argumentos de defensa que esgrime Míguez (2008), creo que su estudio muestra que el recorte sobre una subcultura delictiva, definida por la transgresión, no es un camino apropiado si se quiere dar buena cuenta de las complejidades y variantes de este campo social. Es que, más allá de algunas referencias generales, el autor pasa por alto la necesidad de reflexionar sobre las múltiples consecuencias teóricas del recorte empírico que está implicado en una teoría de la "subcultura". Especialmente cuando, como es el caso, el recorte confirma un proceso de estigmatización (que sin dudas, como lo muestra Míguez (ídem), también es interiorizado creativamente por numerosos actores), mientras que, por otro lado, invisibiliza en el cuantioso mosaico de prácticas que se despliegan entre "la delincuencia" y los exponentes más "convencionales" de los sectores populares, la extensa lista de aquellos sujetos que viven de esas ilegalidades que muchos coinciden en llamar "ilegalismos populares" (FOUCAULT, 2000a). Muy diverso sería el panorama, y el aporte para una sociología, o antropología, política, de incorporarse esas prácticas, ilegales y populares, que nos hablan de una multitud de sujetos habitantes de las fronteras entre lo legal y lo ilegal.

Si al evaluar la relevancia de la "cuestión política" se incluyera en el cuadro analítico la dinámica de estas prácticas, aledañas al delito, sería posible, creemos, encontrar muchos elementos nuevos para discutir, en términos de hegemonía, lo que ocurre con esta "subcultura del delito". Unas prácticas de siempre dudosa legalidad no podrían implicar la misma dependencia simbólica que una identidad definida por su relación con la ley: ni en los términos del "acatamiento", ni en los de la "transgresión" (ERIBON, 2004). Del mismo modo, estas prácticas impiden confirmar la ruptura simbólica entre el delito y lo popular, con lo que es posible hacer de esta escisión un objeto de interrogación y no simplemente pretender constatar, como hace Míguez, que los procesos de santificación popular de bandidos dividen a los vecinos en forma discreta. Pero ante todo, se podría evitar la tendencia - de la que Delito y cultura (MÍGUEZ, 2008) es un claro exponente - a escindir campos sociales y hacer una importante abstracción del contexto sociohistórico. Enraizada en la opción metodológica de este libro está, creo, la completa ausencia de preguntas por la compleja relación que el devenir de esas prácticas y representaciones, analizadas como "variante cultural delictiva", puedan tener con el malestar y los repertorios sociales que sustentaron las importantes expresiones de protesta (saqueos populares, cortes de rutas, puebladas con ocupaciones y/o destrucción de edificios públicos etc.) que protagonizaron los sectores populares urbanos durante los años que cubre el estudio.

\section{SOCIOLOGÍA DEL DELITO O ETNOGRA- FÍA DE LAS TRAMAS POPULARES URBANAS.}

La intención de este apartado es rastrear a través de la reseña de dos etnografías sobre trabajadores pobres urbanos, una verdaderamente clásica (ZALUAR, 1994) y otra todavía contemporánea (ALVITO, 2001), el hilo de una perspectiva etnográfica sobre las tramas urbanas de los barrios de trabajadores pobres que permita eludir exitosamente los obstáculos teóricometodológicos recién señalados respecto de Delito $y$ cultura. Se trata de un abordaje que privilegia la experiencia etnográfica en el terreno y la dimensión de lo urbano por sobre los recortes de "unidades de análisis" abstractas. La riqueza de una perspectiva de las tramas urbanas - en la que sería posible también incluir, entre otros, el trabajo de Fonseca (2004) - como alternativa para el abordaje de aquellas realidades usualmente encorsetadas en la unidad de análisis de la "Delincuencia" o en la mal llamada cuestión de la "Violencia Urbana" fue recientemente puesta de relieve por Telles e Hirata (2007).

Si consideramos importante volver a aquellos textos etnográficos es porque algunos de sus aportes más valiosos aparecen resaltados al colocarlos en una situación de diálogo. Me interesa en este recorrido apuntalar una estrategia teórico-metodológica capaz de "desustancializar" el concepto de delincuencia. Esto es, para reconocerlo en tanto "objeto construido" por la criminología (sociología de la delincuencia), en un incesante diálogo con las agencias de control social duro (policiales, penales y judiciales) del 
Estado. De todas formas, si es cierto que cualquier recorte opera en un determinado nivel de "sustancialización" y "desustancialización" (GUEDES, 1997, p. 27-30), será necesario hacer un breve rodeo y, reconociendo el sesgo del que esta perspectiva es culpable, interrogarnos tanto sobre las ventajas analíticas, como sobre los peligros que involucra esta elección.

En este caso, la afinidad, más o menos explícita según los autores, pero patente en el diálogo posible entre ellos, con una concepción de la "cultura popular" o de "clase trabajadora" permite dejar de lado un criterio trascendente $y$ universal de partición de lo social, aquella gran división estatal entre lo legal y lo ilegal, para tener un acceso a "los agenciamientos prácticos de la vida cotidiana" (TELLES \& HIRATA, 2007, p. 177) en tanto creemos que es una perspectiva capaz de visibilizar criterios inmanentes $y$ singulares. Justamente, si esta perspectiva puede habilitar a cuestionar dichas particiones binarias es debido a su capacidad para dar cuenta de los procesos más o menos autónomos, conflictivos y creativos de conformación de una "cultura popular", subalterna o de clase, diferente tanto de cualquier concepto de subcultura como de cultura convencional (GUEDES, 1997, p. 31; cf. también ZALUAR, 1994; FONSECA, 2004).

Si bien, como ya señalara Thompson (1989), esta cultura de clase trabajadora está lejos de poder representarse con contornos tan definidos como otras formaciones culturales - dado que el mismo proceso de formación de clases en que toma forma es un proceso relacional, antagonista y en permanente mutación - tampoco puede reducirse a los moldes de las definiciones hegemónicas como lo muestran las complejas articulaciones que se dan en su seno entre lo legal, lo ilegal, el trabajo y la delincuencia.

Pero a su vez, al enfocar la dimensión cultural de la formación de clase, como contrapunto fundamental de sus dimensiones políticas y económicas, esta perspectiva no precisa postular a la clase trabajadora como el lugar del "Gran Rechazo" (coordenada única e infalible de toda contestación), como ocurre en algunos razonamientos típicamente deductivos del marxismo (cf. FOUCAULT, 2000b, p. 39-40; 2000c, p. 116), ni recurrir a criterios estratégiconormativos, como los muchas veces involucrados en los conceptos de clase en sí, como conciencia económica alienada, y clase para sí, como conciencia política revolucionaria (THOMPSON, 1989).

En este sentido, creo que el concepto de experiencia de clase resulta clave para la comprensión de esta dimensión cultural de la formación de clase, entendida como "proceso constitutivo de un modo de vida propio" (ZALUAR, 1994, p. 50). En primer lugar, porque introduce el dinamismo histórico de la relación entre formas culturales y los cambios en las experiencias de vida en común, al tiempo que se pone de relieve el peso que en nuestra sociedad tienen sobre ellas las condiciones económicas. Segundo, porque le da movimiento al reconocimiento del carácter contrastativo de las identidades, ya que apunta hacia las vivencias conflictivas en que, en múltiples maneras, se va definiendo la producción simbólica de sí y del otro. Y finalmente, porque al atender al modo en que el tratamiento cultural da forma a nuevas experiencias y transforma las tradiciones, relativiza las formulaciones metodológicas, siempre halagadoras para el mundo "intelectual", que poniendo de relieve la opacidad de la estructura nos ciega al carácter reflexivo y crítico de las simbolizaciones extra académicas.

Así, esta perspectiva habilita - en el último apartado trataré algunos de los ajustes conceptuales involucrados en este postulado - al reconocimiento de un campo cultural encarnado múltiple, aunque delimitable, con distintos agenciamientos sociopolíticos singulares en relación a los cuales se actualiza cualquier transformación de la realidad (sea que funcionen en los límites de políticas estatales, sea de manera autónoma). Y permite, de este modo, cuestionar el paradigma racionalista, predominante en la planificación de políticas estatales que se debate en las trampas del "pasaje de la idea al acto" y cuya capacidad de crítica, a lo sumo, se restringe a las "distorsiones inevitables" de la realización: ¿cuál fue la distancia entre el programa y sus resultados? O, como lo formula Míguez (2008), a las limitaciones del saber: ¿qué conocimientos científicos sobre los fenómenos sociales faltan para elaborar políticas adecuadas? Al contrario, desde esta otra perspectiva se trataría de atender a la heterogeneidad de los procesos y de los sujetos $\mathrm{y}$, a través de ella, a las tensiones que nos hablan de la energía potencial de un sistema, es 
decir, a las virtualidades de un campo de relaciones (SIMONDON, 2009).

Me centraré ahora en el análisis de dos etnografías, A máquina e a revolta de Alba Zaluar (1994) y As cores de Acari de Marcos Alvito (2001), que tienen entre sus hilos centrales las tramas sociales entre trabajadores y "bandidos" en diferentes barrios pobres de la ciudad de Rio de Janeiro, una en la década de los 80 s y la otra en los 90s. Me detendré tanto en la conceptualización teórico-metodológica de estos abordajes, intentando tomar y resaltar aquellos aspectos que informan la perspectiva recién apuntada, como en algunas transformaciones históricas que las etnografías acompañan y que resultan significativas para las preguntas que nos hacemos. Por último, intentaré inscribir lo que entiendo es una pregunta fundante de esta perspectiva etnográfica, que apunta a una serie de prácticas ilegales ligadas al tejido social del que se las intenta separar con el concepto de "criminalidad", a través de la puesta de relieve de sus vínculos con una línea de la llamada economía política de la pena.

\section{LAMÁQUINA Y LA REVUELTA}

Alba Zaluar se aproxima al conjunto habitacional Ciudad de Dios con el objetivo de estudiar "el modo de vida de las clases populares urbanas" (ZALUAR, 1994, p. 9) y en particular sus "formas de organización" (idem, p. 33) ${ }^{1}$. Luego de fracasar en el intento de entablar una relación de investigación con las asociaciones de moradores de la zona, la autora encuentra en una agremiación cultural, un bloco de samba, el espacio alternativo para el desarrollo de su trabajo de campo.

Retomando una larga tradición de las ciencias sociales críticas, Zaluar "investiga cuál es la visión de la sociedad y la política desde abajo" (idem, p. 44). Así, elude la tentación de presentar un modelo único y coherente de su ideología en detrimento de las tensiones internas, sus divisiones, sus conflictos. Pero también, el etnocentrismo que pretende medir la organicidad y la politización de los pobres urbanos con la regla de la política institucional dominante, propia de las clases "integradas". Se trata, en cambio, de describir y

1 Todas las citas en español de los textos en portugués son de mi traducción. analizar sus formas propias de organización y protesta. Esto implica, por supuesto, poner en primer plano los mecanismos institucionales involucrados en la relación entre los trabajadores pobres, las otras clases y el Estado. Y de este modo, la situación de estigmatización, en que algunos análisis terminan relamiéndose, es reenviada, como momento particular, a una trama relacional.

Si bien es cierto que las teorías sobre el "populismo" han tratado en extenso, y con ciertos matices, la relación de los trabajadores pobres con el Estado, estas terminan en una tautología dado que la pobreza sigue siendo el locus explicativo privilegiado para la manipulación política. Lo mismo ocurre con los análisis del fenómeno del "clientelismo" cuando éste es tratado como exclusivo y concluyente respecto de los sectores populares. Sin embargo, su evidente dispersión por todo el campo social, incluyendo especialmente al sistema burocrático, debería llevar a preguntarse qué otras prácticas protagonizan los sectores populares (idem, p. 4548).

En esta perspectiva encontramos una interesante lectura política de las prácticas cotidianas de los trabajadores que, entre otras cosas, ofrece una clave de intelección para vincular las prácticas organizativas populares, los saqueos a supermercados y las formas locales de vincularse a "la política", con fenómenos tales como el apoyo electoral al revoltado Brizola (que sin recursos clientelares consigue la gobernación de Rio de Janeiro mientras Zaluar realiza esta etnografía). Entonces, el abordaje de Zaluar propone tomar como objeto de interés el proceso social de construcción creativa de la identidad de "trabajador pobre", lo que implica poner de relieve su cultura "entendida como proceso constitutivo de un modo de vida propio" (idem, p. 50). Esta perspectiva se nutre, entonces, de un concepto de hegemonía (idem, p. 56) capaz de dar cuenta tanto de la situación de dominación de una cultura oficial con su espacio público, como de la relativa autonomía de una cultura popular propia de los trabajadores pobres y constitutiva de un "espacio público pero exclusivo a los subalternos, excluidos y marginados" (idem, p. 57).

Ahora bien, ¿qué lugar ocupa, en esta perspectiva etnográfica sobre los trabajadores pobres de Ciudad de Dios, aquello que al comienzo 
señalábamos como el objeto cuya desustancialización era de nuestro interés, a saber, lo que los dispositivos de control estatal recortan como "delincuencia"? Es que "Las divisiones internas del conjunto - sus áreas, sus calles y plazas - así como la separación entre trabajadores y bandidos forman parte del proceso social de construcción de la identidad de trabajador, con todas sus ambigüedades y tensiones, y de constitución de sus organizaciones, en las que practican la política y piensan sobre ella" (idem, p. 51).

Después de describir la formación del complejo de Ciudad de Dios, situado al interior de las políticas habitacionales y los procesos de remoción de favelas en Rio de Janeiro en las décadas anteriores, y luego de analizar las características generales de las condiciones de vida de sus habitantes, apoyándose en una interesante lectura del ciclo doméstico y sus prioridades para entender la relación con el clientelismo, así como resaltando las formas en que interactúan, marcando toda la geografía, la dinámica de la cultura popular frente al planeamiento estatal, la autora se detiene en las representaciones y prácticas de los trabajadores que remiten a su cotidiano, lo que aquí más nos interesa.

En su investigación va cobrando relevancia el concepto local de "revolta", en la medida en que descubre su rol de mediación entre la identidad social de trabajador y la de bandido. El uso significativo de este concepto no pertenece con exclusividad a una de estas dos figuras sociales y permite comprender el carácter múltiple de la cultura popular, las formas variadas en que se la conjuga. Para empezar, señalemos que este término se utiliza, ampliamente, para expresar el rechazo a participar de relaciones sociales que hieren el sentido de justicia o la dignidad. También se aplica a las personas que resuelven cuestiones personales con métodos violentos $\mathrm{y}$, del mismo modo, a los bandidos. Pero este concepto también era utilizado cuando se explicaban los saqueos en masa a supermercados diciendo "o povo revoltou".

Como dijimos, la revolta nos pone sobre el hilo de las relaciones entre trabajadores y bandidos al interior de un mismo proceso de formación cultural. Así, la autora, al margen de señalar una lucha entre la justificación del robo y el orgullo de ser trabajador (1994:121), resalta con insistencia la presencia de una voluntad de juzgar que no puede reducirse al modelo abstracto y universal de la justicia estatal o burguesa (idem, p. 133, 140, 143 y 206). Las relaciones entre trabajadores y bandidos se muestran mucho más "complejas y ambiguas" tanto al nivel de las representaciones como al de las prácticas (idem, p. 133).

La primera paradoja que conduce a la etnógrafa por este camino son los discursos sobre un "personaje importante del lugar" Manoel Galinha. Este bandido era el responsable de la estigmatización del lugar como una zona peligrosa, pero al mismo tiempo era muy respetado y querido por los vecinos. Como habitante de ese lugar, el "bandido formado" conoce a la gente y respeta las reglas de convivencia de los trabajadores, en particular, no vulnera la dignidad masculina aprovechándose del hecho de estar armado. En suma, tiene "moral" (idem, p. 138 y 144)

Esta paradoja se apoya en otra, relacionada a las prácticas, porque entre trabajador y bandido es posible reconocer una "simbiosis" (idem, p. 138) desde el momento en que el bandido formado defiende el lugar de las humillaciones que pueden causar bandidos "no formados" o bandidos "extranjeros", de otras zonas. Así, el bandido puede ser el defensor de los trabajadores en un contexto en que la acción policial y judicial es inexistente o directamente pervertida. No sólo evitando humillaciones, sino incluso evitando que un trabajador honesto se involucre en un crimen al verse en juego su honor (tomando la venganza el bandido en lugar de éste). Esta mediación delictiva-popular se da al interior de un ethos de la honra masculina que diferencia el "intercambio de ideas" del "dar órdenes" y el "vencer en la moral" del "vencer en la cobardía". Una honra que al resaltar el valor positivo de las relaciones entre iguales rechaza al plano de la inmoralidad tanto la "fuerza bruta" policial como delictiva (idem, p. 140-141). Ya empezamos a reconocer que la fuerza bruta, o la violencia, no es condenada por una cualidad sustancial, o con arreglo a las leyes de un desarrollo "civilizatorio" (ELIAS, 1994b), sino cuando no puede ser controlada de acuerdo a unas reglas de convivencia local fundamentadas en el conocimiento personal (MÍGUEZ, 1994, p. 140 y 165). Así, matar una persona no es juzgado de acuerdo a criterios formales y universales, sino que puede ser 
correcto o errado, en términos morales, de acuerdo a la identidad de las personas involucradas y a la situación (idem, p. 143-144).

Por contrapartida, al analizar la relación entre bandidos y jóvenes (ya no trabajadoresproveedores), la autora encuentra una realidad que propone leer como un "ethos de la honra pervertido" (idem, p. 142). El orgullo de los bandidos jóvenes que exhiben su máquina en la cintura y consideran "la disposición a matar", lo que para los trabajadores es cobardía, como un símbolo de coraje (idem, p. 141). También la relación de protección de los bandidos con los jóvenes tiene un signo muy diferente que con los trabajadores proveedores. En caso de haber sido humillado, aquellos le ofrecerán un arma en préstamo para que recupere su honra por sí mismo. Del mismo modo, los jóvenes desempleados pueden ganar algún dinero haciendo mandados para las cuadrillas, o directamente "entrando" al tráfico de drogas. En este sentido, la autora entiende que en el lugar hay "dos sistemas de socialización en competencia”, pero ninguno de ellos corresponde a una cultura convencional (idem, p. 154).

Sin embargo, sigue estando claro que el tráfico, ante todo, es un negocio (idem, p. 165). Y aunque la historia del bandido que se enriquece es en verdad muy rara (la mayoría muere joven), la prosperidad que brinda el tráfico y las relaciones que genera con los "nenes de papá" que llegan a la favela a comprar drogas, produce cambios importantes en las aspiraciones, la actitud y las formas de vestir (idem, p. 157). A pesar de esta distinción creciente, la autora encuentra que, en una etapa de crisis y baja salarial ${ }^{2}$, tanto la visión que estigmatiza desde fuera, como la revolta do povo desde dentro (en los saqueos a supermercados) diluyen cada vez más la diferencia entre trabajador y bandido (idem, $\mathrm{p}$. 162).

\section{AS CORES DE ACARI}

Al igual que en el apartado anterior, recorreremos aquí una etnografía sobre la vida en un conjunto urbano de trabajadores pobres, rastreando algunos elementos que resultan

\footnotetext{
2 Tal vez por una limitación del enfoque etnográfico, la importancia de los cambios del ciclo económico no aparece lo suficientemente resaltado en ninguno de estos trabajos.
}

significativos para el hilo de este artículo. Nos haremos eco de algunas redundancias, pero atenderemos especialmente a las diferencias, palpables en la mirada del etnógrafo y en la realidad histórica que analiza.

Cuando Marcos Alvito (2001) llega a la favela de Acari arrastra una serie de preguntas que, fogueadas en relación a contextos tan diversos como la Antigua Grecia y la Penitenciaría Lemos Brito, terminarán marcando el camino de su investigación. Y no lo hace caprichosamente, porque ya en los primeros contactos con la realidad en que emplazará su trabajo etnográfico, encuentra "las características centrales de una cultura de la honra y la vergüenza" (idem, p. 19). Así, es que decide dedicarse a la reconstrucción de una "memoria' de los buenos tiempos" que leída a contrapelo habla en un registro mucho más preocupado sobre el presente que sobre el pasado $\mathrm{y}$, a la vez, resulta ser una estrategia interesante para evitar que una investigación tan centrada en prácticas ilegales, ya que "el tráfico" resulta un elemento central de esa configuración cultural, se confunda con una investigación policial (ibidem). De hecho, durante 1996, en pleno trabajo de investigación Acari fue ocupada por la policía lo que permitió el registro de una situación de cambio en las relaciones sociales que no podía ser prevista a la hora de construir sus preguntas. El uso de fuentes periodísticas complementa un trabajo de campo que recorre las calles deteniéndose en asociaciones de moradores, organizaciones deportivas o de recreación y centros religiosos para reconstruir las mallas de relaciones que presenta vivamente en su etnografía. Allí, las marcas del tráfico y la policía son omnipresentes.

Después de describir el "escenario" de su campo, deteniéndose en una multiplicidad de marcas simbólicas cuyos significados sólo se van desgranando bien adentrados en la etnografía, y complejizando las miradas homogeneizadoras sobre Acari (que en realidad comprende cuatro espacios diferentes bien delimitados cada uno con una multiplicidad de "micro áreas" esenciales para entender la vida de sus habitantes), Alvito (idem) se detiene en un denso análisis de las relaciones entre las cuadrillas de traficantes y la policía. A diferencia de lo que encontrábamos en la etnografía de Zaluar, y tal vez por un proceso de separación entre bandidos y trabajadores, aquí se sugiere que "en la lógica de una guerra entre 
'facciones' (término 'nativo'), muchas veces la policía, sobre todo la Policía Militar, es vista como una tercera fuerza" (idem, p. 75). "TC" (Terceiro Comando), "CV" (Comando Vermelho), y "PM" (Polícia Militar); Verdes, Rojos y Azules; símbolos y colores que marcan las paredes y señalizan el territorio de la favela (idem, p. 93).

Nos encontramos ante una escalada en la violencia, que ya era visible en la década de 1980, pero que ahora es abordada desde un discurso que elabora una imagen de "guerra" entre "ejércitos" que profundiza en la banalidad de las muertes antes apuntada y coquetea con una idea de "equilibrio de fuerzas" entre traficantes y policía que da un paso más allá respecto de la equivalencia en el rol, que encontraba Zaluar, del "bandido formado" como sustituto del policiamiento ostensivo. Sin embargo, esta "imagen" todavía es externa. Rápidamente se encuentran muchas continuidades entre esta etnografía y la precedente.

Vemos entonces que, nuevamente, es necesario aumentar la escala de observación para llegar al cotidiano de los trabajadores e interrogar los vínculos y las representaciones locales. "Aquello que es presentado diariamente en la prensa como una estructura supralocal es, de hecho, un conjunto de oposiciones y alianzas entre bandas de traficantes enraizados localmente. En suma, lo que hay son relaciones interlocales" (idem, $\mathrm{p}$. $83)$.

La imagen hegemónica de los "traficantes" como "terroristas" fue esencial para la política de seguridad pública que llevó a la ocupación policial de 1996 (idem, p. 85). Sin embargo, a nivel local la estrategia policial fue ocupar el mismo papel que los traficantes: “Así, la guardería infantil antes mantenida por el traficante es 'adoptada' por un batallón de la PM" (idem,p. 86). Del mismo modo, las bases de la policía se montan en los lugares donde había bocas de venta de droga (bocas de fumo) o en casas que pertenecían a traficantes. Tanto así, que "quedamos sin saber si era el tráfico el que antes asumía la función del Estado o si es el Estado el que ahora pasa a asumir la función del tráfico" (idem, p. 88). Y teniendo en cuenta que son los PM - que en el imaginario hegemónico comienzan a ser vistos como el equivalente estatal de los traficantes en una guerra de ejércitos - los que cumplen esa función, no es raro que el autor se incline por la segunda opción. "Tres años después de efectuada la ocupación policial de Acari (escribo en mayo de 1998), la 'invasión social' todavía no había llegado" (ibidem). Así, tampoco es de extrañar que los habitantes identifiquen en muchos aspectos a traficantes y policías. Mucho tiempo antes de la ocupación policial, ya tenían elementos para esta identificación en las numerosas alianzas entre cuadrillas de traficantes y determinados batallones de PMy en la utilización de las mismas técnicas: secuestros, tortura, robos, castigos corporales, restricción de la libertad civil, violaciones etc. (idem, p. 96-100).

Llegado a este punto, también Alvito reconoce la importancia de atender a una ética con la que se juzga el accionar de Azules, Verdes y Rojos. Aunque esta ética no es calificada como "popular", en cambio es referida continuamente al trabajo de Alba Zaluar. Así, nos encontramos nuevamente con la afirmación de que "según la lógica de la honra, la acción policial no es rechazada por su violencia o por la transgresión a los derechos: a los ojos de los miembros de la comunidad, la acción policial es absurda por no respetar la jerarquía local, por vejar a los jefes de familia adelante de sus amigos y parientes, y lo mismo vale para la cuadrilla [de traficantes] venida 'de fuera', que desconoce 'quién es quién'. Una ética para la que ciertas distinciones son fundamentales: 'cada uno es cada uno', bandido es bandido, trabajador es trabajador". Y donde la violación aparece como sinónimo de violencia, como límite último de la honra, en tanto representa un caso extremo de "uso de la fuerza contra la persona errada" (idem, p. 100).

Tras recorrer las diferentes anécdotas y trayectorias individuales con que Alvito presenta la trama organizacional de Acari, incluyendo tanto asociaciones de moradores, como templos de las más variadas religiones que pueblan la favela, queda claro que la presencia del tráfico tiñe todas las relaciones sociales. La emergencia de un "neoclientelismo" que acompaña la pérdida de representatividad de las asociaciones de moradores bajo la influencia del poder del tráfico, se corresponde con la creciente rentabilidad de ese negocio a partir de la década de 1980 y el aumento del poder local del dono, el jefe del tráfico, hasta el punto de representar efectivamente la comunidad (idem, p. 159, 162). La demonización de los cultos afro-brasileros y la hegemonía evangelista también se recortan, aunque no se reduzcan a ello, sobre el molde de 
la lucha contra el narcotráfico y campañas mediáticas de moralización (idem, p. 215). Sin embargo, queremos llegar pronto al punto en que esa cultura de la honra y la vergüenza, en la que destaca un ethos masculino (idem, p. 143ss.), involucra a las cuadrillas de traficantes. Creo importante volver a resaltar que si bien Alvito no se pregunta por una cultura popular vinculada a una identidad de "trabajadores pobres" ambigua pero capaz de relativa autonomía, sí recorta su objeto como "un análisis de las representaciones de la comunidad acerca de las cuadrillas de traficantes" para mostrar "que las ideas de honra, jerarquía y reciprocidad son fundamentales en este proceso continuo de renegociación de papeles y espacios entre la comunidad y el tráfico" (idem, p. 219). Aunque ahora la categoría "cultura de la honra de la comunidad" reemplazó (sin ninguna explicación de por medio) a "cultura de los trabajadores pobres", nuevamente nos encontramos sumergidos en esa realidad gris de la que también lograba dar cuenta Alba Zaluar ${ }^{3}$.

Alvito nos sumerge en el gris de las relaciones trabajadores-bandidos a través de una suerte de mitológica (idem, p. 243). Se trata de reconstrucciones del pasado que tienen la característica de trabajar a partir de las reglas de un código de valores, lo que por un lado facilita el acceso a la relación entre la moral de la comunidad y las prácticas de los bandidos y por el otro evita la confusión entre la etnografía y la indagación policial. Así encontramos que hay una serie de elementos míticos que se repiten, aunque con sutiles variaciones, en los relatos sobre diferentes bandidos donos de favela. Estos relatos llevan al autor a postular una suerte de mezcla virtuosa entre trabajadores y bandidos, que en su expresión más pura implica una clara división del trabajo moral. Así, "los 'buenos' jefes son blanco de

\footnotetext{
3 Uno podría preguntarse aquí la relación entre este cambio y aquel propio de las "sensibilidades" de los investigadores que cuya problematización hace Fonseca al reconocer que "lo 'popular' decididamente no está en la orden del día" (FONSECA, 2004, p. 218). Luego de las críticas al concepto de clase en la década de 1970 y al de popular en la década de1980, este campo de estudios de las tramas urbanas parece haber entrado en estado de negación del problema por omisión. “¿Dónde están los debates capaces de profundizar nuestra comprensión de las alteridades inscritas en el juego de la estratificación social?" se pregunta Fonseca (ibidem).
}

representaciones colectivas según las cuales ellos habrían abrazado una actividad ilegal en nombre de la honra" (idem, p. 241).

Paradójicamente esta mezcla virtuosa, este punto específico de indistinción, sustenta la permanencia de la honra local porque distingue correctamente "quién es quién". Respeta esa ley no escrita de la reciprocidad y vela por la honra de las familias (idem, p. 241-242). Evita la mezcla generalizada entre trabajadores y bandidos $\mathrm{y}$, sobre todo, evita la mezcla entre trabajadores y viciados (ya hablaremos de ellos). Resuena nuevamente en esta presentación la serie presentada por Zaluar (1994): "trabajador", "bandido formado" y "bandido porco"; sólo que ahora con la forma: "trabajador", "dono del tráfico" y "viciado". En ambos casos, el término medio no funciona como puente sino como barrera. En lo que parecía un punto intermedio en un degradé, tenemos el cerrojo de una ruptura moral. Es, de hecho, el hiato que permite mantener la honra libre de contaminación, en tanto y en cuanto, ellos mismos, a pesar de pertenecer al mundo impuro, son héroes de la honra: se acercan al modelo de sujeto-hombre (independiente, viril, corajudo, honesto y responsable-proveedor) que en gran parte comparten con los líderes comunitarios, aún si por esa "marca" trágica quedan expuestos al mundo de los "vagabundos" (ALVITO, 2001, p. 143-146). Sin embargo, esta visión sistémica del mundo moral remite al pasado, un pasado idealizado que va quedando atrás dejando lugar a un futuro que amenaza este equilibrio.

La presencia de jóvenes portando armas de fuego, no sólo representa un problema en relación al respeto de la comunidad, sino que introduce elementos nuevos. Para empezar, y como ya lo señalara Zaluar (1994), los meninos implican una inversión completa en la jerarquía de las clases de edad, contra el poder de las armas los mayores no consiguen obediencia (ALVITO, 2001, p. 258). Pero además, después de la muerte del último dono, quedó evidenciado, detrás de sucesivos asesinatos dentro de la misma cuadrilla, que muchos de los valores adjudicados a los bandidos ya no tenían vigencia para ellos. Respecto del sucesor, comentan a Alvito que "no tuvo ningún escrúpulo en matar a dos amigos de la infancia con quienes compartía el comando: 'él no respeta madre, no respeta padre, no respeta nada" (idem, p. 259). Sin ningún pasado que exponer como previo a la deshonra del crimen, su entrada al 
tráfico no tiene ninguna connotación moral en las representaciones que circulan sobre ellos: se trata de diversión, disfrute, mujeres y dinero; intereses individuales. Los meninos sin ninguna posibilidad de derecho a la virtud, tampoco parecen pretenderla. Las violaciones y humillaciones a trabajadores vuelven a ser noticia. Parientes de bandidos, sin una historia de trabajadores que se revoltan detrás de ellos, son presentados por la comunidad como "endógenos" al tráfico (idem, p. 260). Al parecer, toda la compleja trama que existía entre trabajadores y bandidos se desvanece en el aire. Predomina el fetichismo de las armas (idem, p. 112).

No resulta causal que, al tomar el poder, este último "dono" destruyera todos los santuarios religiosos afro-brasileños que habían construido sus antecesores, ellos representaban la "unión" (un elemento fundamental del orden en ese territorio heterogéneo y con tantas historias de "guerras" que también es expresado por otros tantos símbolos que se describen a lo largo de la etnografía). Si como sugiere Marcos Alvito, retomando a Hannah Arendt (1994) al final de su libro, no sería tanto la violencia lo que tenemos que mirar con atención sino el poder, entonces es posible pensar esas profanaciones como el necesario correlato simbólico de la destrucción del poder, entendido como violencia legítima fundamentada en un acto de unidad, y la inauguración de una violencia del terror (ALVITO, 2001, p. 283-284).

Antes del ocaso de ese poder legítimo no era imposible reconocer la autoridad del jefe por sobre las armas de fuego, y tampoco las múltiples negociaciones con los líderes comunitarios. Ahora, ante el dominio puramente violento, no deberíamos, de acuerdo a la conceptualización propuesta, quedar estupefactos, sino escuchar el modo en que esta forma de violencia nos está hablando de la debilidad de aquel poder. Alvito no lo aclara, pero resulta evidente. Se trata del ocaso de una forma de poder local, ¿popular?, que poco y nada tenía que ver con ese "poder paralelo" del que hablaban las noticias (idem, p. 88). Y si, aunque dudo, estoy tentado de utilizar el adjetivo "popular" para referirme a esta forma de poder local, es porque su suerte se corresponde con el espacio de aquella cultura popular de la que hablaba Zaluar y que Alvito describe en forma brillante como cultura de la honra, y en la que no es posible escindir en un binarismo trabajadores y bandidos. Lo que queda claro es cómo este espacio moral, fundado y refundado, sin un poder en que apoyarse, comienza a perderse y desintegrarse, al tiempo que la escisión entre trabajador y bandido se vuelve discreta. La figura del bandido endógeno, sin mezclas con la del trabajador, rompe el equilibrio al borrar las distinciones del "quién es quién" propias de la cultura popular.

\section{EL CONTROL EN LA FILIGRANA DE LA VIDA}

Más allá de sus particularidades, estos dos casos, con sus variaciones metodológicas y empíricas, nos permiten entender la extensión de unas tramas mucho más complejas que las distinciones binarias de lo legal y lo ilegal, de lo regular e irregular, de lo convencional y lo subcultural.

Volviendo al problema planteado en el segundo apartado, espero que ahora ya esté claro cuál puede ser la productividad de un enfoque centrado en el espacio urbano para la comprensión y dessimplificación de lo que se entiende por delito. Estamos muy lejos aquí de las encuestas y entrevistas guiadas por la unidad de análisis: la "delincuencia", presentadas por Míguez. Al contrario, vemos como esta supuesta "unidad" está completamente atravesada con las formas culturales locales (que sin dudas deben estudiarse empíricamente en las diferentes tramas urbanas). En todo caso, queda como una constante entre los diferentes trabajos la constatación de fenómenos extremos vinculados a la ocupación policial, o fuertes lazos con miembros de esa institución, y que sin dudas habría que estudiar mejor atendiendo especialmente a la dimensión generacional o etaria que es posible reconocer tanto para el caso de Rio de Janeiro como Buenos Aires. Es cierto, por otra parte, que en estas etnografías no se profundiza aún en los efectos que la precarización laboral o la informalidad del trabajo, como decía antes, tienen sobre el cotidiano de los trabajadores urbanos y su relación con las agencias de control. Sin embargo, las piezas esenciales de un abordaje etnográfico sobre los grises de las tramas populares urbanas ya están en ellas presentes. No ahondaré más en ello.

En cambio, me parece interesante señalar el modo en que estos abordajes se encauzan con una corriente de la criminología crítica conocida como economía política de la pena - corriente 
que, con trabajos dispares y diferentes recorridos, toma como centro de análisis la relación entre trabajo y delito (DE GIORGI, 2006, p. 53-86). En particular, creo significativo que nos detengamos en el concepto de delincuencia que Foucault (2000a) vincula al nacimiento de la prisión. Sabemos que desde su perspectiva, la prisión, como todo dispositivo de poder, es interrogada en su productividad. Pero, ¿cuál es su producto por antonomasia? Aunque en los comentaristas no haya un total acuerdo al respecto, dado que el concepto de "disciplina" que se elabora en el análisis excede y antecede por mucho a la prisión (DE GIORGI, 2006, p. 116), él mismo, en más de un lugar, responde con claridad esta pregunta: "la delincuencia" (FOUCAULT, 1999, p. 247-249; 2000a, p. 282). "El sistema policíaprisión aísla una delincuencia manejable" (FOUCAULT, 2000a, p. 287) que permite, por un lado, una gestión diferencial de los ilegalismos (para poder explotarlos, especialmente a aquellos "ilegalismos privilegiados" como bien resalta Acosta (2004), pero que ante todo, rompe aquella indistinción entre lo ilegal y lo popular propia de los ilegalismos populares del siglo XIX y comienza a utilizar la delincuencia en contra de las luchas populares (FOUCAULT, 2000a, p. 285). La delincuencia implica, en esta perspectiva, una ruptura de lazos en la trama de la cultura popular. Una escisión apoyada en el proyecto estatal de partición entre lo legal y lo criminal. Un quiebre que se apoya tanto en una "moralización" de los sectores populares como en una "especialización" de los delincuentes (idem, p. 291).

Es justo preguntarse, como lo hace Zaluar (1994, p. 133), en qué medida esta constatación permite totalizar, en un momento dado, la relación entre pobres e ilegalidad. Sin dudas, esto es algo que no ha sido analizado por Foucault, su análisis sobre las disciplinas parte del intento de reconocer lo que sí funciona en el sistema penal (su aspecto productivo), en tanto que ya desde su nacimiento estaba claro que éste no funcionaba de acuerdo a sus metas explícitas, es decir, fallaba como un mecanismo de resocialización ${ }^{4}$. En cambio, esta

\footnotetext{
4 Aunque también es claro que nunca postuló la posibilidad de esa totalización y el grueso de las críticas que le dirige Zaluar (1994, p. 133) son injustificadas. Como prueba baste una cita: “[...] sin embargo, no han dejado de encontrar resistencias; han suscitado luchas y provocado
}

pregunta, que podríamos pensar como interrogante sobre la tensión efectiva, y encarnada en las ambigüedades del cotidiano, entre la cultura popular y la hegemonía estatal, es ampliamente abordable desde la perspectiva etnográfica que retratamos aquí, y tiene plena actualidad ante los cambios que se operan en el mundo del trabajo.

El juego propuesto entre estas perspectivas, una de las cuales es la historia desde abajo propuesta por Thompson (1989) y la otra al análisis microfisico de las relaciones de poder de Foucault (1979), requeriría, sin dudas, no pocos ajustes conceptuales. A pesar de ello, implica de entrada no aceptar una serie de lugares comunes. Por un lado, si bien es fácil coincidir en que la perspectiva de Thompson tiene un matiz empirista, y son varias sus dificultades a la hora de desarrollar las complejas discusiones teóricas que propone (ANDERSON, 1985), justamente es la riqueza y originalidad con que analiza y desarrolla su trabajo empírico, su inclinación metodológica más que sus síntesis conceptuales, lo que ha servido de mayor inspiración en el campo académico. Particularmente la valorización que hace del cotidiano al (re)integrar la dimensión cultural en la conceptualización marxista de las clases, para conjugar el modo en que "unas gentes" experimentan la explotación y su propia lucha. Pero también, la forma en que consigue atender a experiencias alternativas o, llegado el caso, contra-hegemónicas por fuera del discurso normativo y tautológico de la "clase revolucionaria" (donde es una teoría llegada de fuera la que define qué es la conciencia de clase para sí, como en el Lenin del ¿Qué hacer? (LENIN, 2001). En suma, la mirada desde abajo que propone es sin dudas una mirada que capta lo micro (la experiencia de las gentes) para lograr una lectura más rica de la dimensión macro (justamente el concepto de lucha de clases que le permite totalizar un período histórico).

reacciones. Levantar la barrera que habría de separar a los delincuentes de todas las capas populares de las que habían salido y con las cuales se mantenían unidos, era una tarea difícil, sobre todo sin duda en los medios urbanos. [...] Pero esta táctica está, sin embargo, lejos de haber triunfado, o en todo caso de haber obtenido una ruptura total entre los delincuentes y las capas populares. Las relaciones de las clases pobres con la infracción, la posición recíproca del proletariado y de la plebe urbana habría que estudiarlas" (FOUCAULT, 2000, p. 291-293). 
Por el otro lado, numerosas críticas se han erigido contra la mirada foucaultiana para señalar su incapacidad inherente para captar y dar un justo tratamiento a las resistencias, precisamente en lo que refiere a una "cultura popular" (GINZBURG, 1999, p. 14; en un texto escrito en simultáneo con la publicación de Vigilar y castigar). Sin dudas, estos cuestionamientos se apoyan en aspectos importantes de la obra de Foucault, pero no dan cuenta de su trayectoria intelectual. De hecho, en una de sus últimas intervenciones reconoce la posibilidad de encarar los mismos objetivos analíticos a través del estudio de las resistencias (FOUCAULT, 2001, p. 243-244). Y más aún, existen lecturas de su obra, que nos desafían con la necesidad de pensarla en su integridad, y colocan el concepto de "experiencia", una experiencia en conflicto con las técnicas de poder, como eje articulador entre sus diferentes etapas (FORTANET, 2008). Foucault nunca dejó de reconocer algo que escapa a los mecanismos de poder (y no al poder, dado que nunca se trata de él). Sugerentemente, en más de una oportunidad (FOUCAULT, 2000a, p. 293; pero sobre todo 1992a, p. 117), intenta nombrar eso que resiste utilizando el mismo nombre con el que Thompson (1989) cualifica un sector de la sociedad inglesa del siglo XVIII que tiene la característica de experimentar la lucha de clases antes de la formación de las clases propiamente dichas, esto es: la plebe. En ambos casos es un concepto anacrónico, pero que permite salir del molde sociológico para indagar procesos complejos. Es evidente que no podemos tratar en este lugar las diferentes variaciones que el problema de la resistencia presenta en la compleja obra foucaultiana. Aunque no está demás apuntar que en los años que transcurren entre este reconocimiento de la plebe como figura filosófica que permite hablar de aquello que se "desgaja" del poder, contragolpe de las relaciones de poder, y su conceptualización de una posible vía de análisis del poder a través de las resistencias hay un cambio fundamental en lo que refiere a la posibilidad de una "estrategia de lucha" por parte de las resistencias (FOUCAULT, 2001, p. 258259).

Sin embargo, tal vez sí corresponde detenerse un poco más en este concepto de "experiencia" presente en Foucault dado que si bien en ambos autores el análisis funciona en el horizonte de una teoría de la emancipación, en Thompson simplemente amplia el horizonte de la visión marxista sobre los explotados (permitiendo a diversos historiadores pensar fenómenos malditos, $v$. g. el "peronismo" en James (1990)) mientras que en Foucault, generalmente, parece haber un ruptura radical con esta tradición teórica (para indicios claros en sentido contrario ver Foucault (1992b, p. 109)) o al menos una apertura hacia otras problemáticas.

En primer lugar, repasemos brevemente el sentido ético-político latente en este concepto de experiencia foucaultiano. Es interesante para esto confrontar dos lecturas acerca de este problema dado que plantean una discusión sobre un asunto que consideramos de interés a lo largo de este artículo. De acuerdo con Fortanet (2008), el concepto de experiencia resulta fundamental para establecer una coherencia entre los diferentes momentos de la obra de Foucault. Aunque reconoce que este concepto cambia de modulación y situación, en ese trayecto intelectual, postula, en cambio, que hay un concepto que se mantiene y permite articular un nudo de coherencia en la obra. Este concepto es la formulación filosófica de la experiencia, ya en la Historia de la locura (FOUCAULT, 1967), como “experiencia límite". Así, propone "comprender la tarea foucaultiana como una historia de las experiencias, y más concretamente, siguiendo el título de R.D.Laing, como una politización de las experiencias" (FORTANET, 2008, p. 20). Ahora bien, nos preguntábamos, dado nuestro interés de método, cuál es el sentido de esta politización. Fortanet lo sintetiza de este modo: "Sin duda, el primer Foucault apelaba a una experiencia fenomenológica en tanto experiencia vivida, pero ya en su Historia de la locura dicha experiencia es dejada de lado para abrazar una idea de experiencia que no quede atrapada en la conciencia individual y cartesiana y que, en líneas mayores, arrastrará el resto de su obra: la experiencia del límite o transgresión, posteriormente traducida en experiencia política, resistencia o pensar de otro modo" (idem, p. 21; grifos en el original).

Sin embargo, es la traducción de esa problemática de la transgresión en otra clave lo que no es captado suficientemente por este autor. Como vimos una inclinación metodológica centrada en la transgresión, en el mejor de los casos, como señala Ginzburg, "lleva a preguntarnos si "la cultura popular existe fuera del gesto que la suprime"” (GINZBURG, 1999, p. 
14). Ya que, si al identificarla con la transgresión, por un lado, denuncia la exclusión que hace posible el orden, en contrapartida, reduce lo que excede el orden a la negación de la norma (por ejemplo, los ilegalismos populares a la delincuencia). Este mismo razonamiento está detrás de aquellos textos donde Foucault niega la posibilidad de una "estrategia" de resistencia (p. ex. FOUCAULT, 1992a). Como vimos, esto no puede aplicarse a toda su obra. Entonces, si bien un concepto de experiencia no fenomenológica, sino históricapolítica, está presente en su búsqueda, aun resta indagar, cuál es la matriz de esa lectura y cómo se puede vincular con la problemática de la cultura popular.

Didier Eribon (2004) señala el primer volumen de la Historia de la sexualidad (FOUCAULT, 2000c) como el punto de inflexión donde se presenta con claridad el quiebre entre Foucault y una política de la transgresión fácilmente identificable con la obra de Bataille (quien, junto con Sade, pasa de ser visto como subversivo a ser presentado como una expresión del mismo viejo orden). Precisamente en la medida en que el ejercicio del poder deja de tener como centro exclusivo, o primordial, la prohibición, las contestaciones de este ejercicio dejan de pasar centralmente por la transgresión, y pasan a estar basadas en la producción de sí y la "creación de espacios" alternativos (ERIBON, 2004, p. 67). En suma, para este autor la trayectoria foucaultiana sólo se comprende atendiendo a los acontecimientos del movimiento gay (en particular, el pasaje de una situación de censura a la posibilidad de crear ámbitos propios). Si esta trayectoria permite, ahora sí, pensar una estrategia de lucha, la misma está centrada especialmente en el enfrentamiento de la sujeción (más que la dominación o la explotación). Es decir, en una política de lo minoritario.

Esto nos lleva a entender, por qué hay un persistente rechazo a pensar esas experiencias micro en una traducción capaz de definir y dar sentido, si no a la Historia, al menos a un contexto histórico, es decir, en los efectos macro que ellas producen. En más de una oportunidad Foucault rechaza la idea según la cual las totalizaciones puedan tener algo que ver con la emancipación (FOUCAULT, 1992c). Y, de hecho, sus enunciados más totalizantes remiten a formas de dominación, donde queda borrada toda resistencia (v. g. sociedad disciplinaria). Sin embargo, el mismo autor plantea que los cambios en las formas de ejercer poder sólo se explican por las resistencias, por lo que escapa a los mecanismos de poder, por el fracaso de las tecnologías de poder. Pareciera que no hay una articulación acabada de este problema en su obra, y no es de asombrar teniendo en cuenta el dinamismo que tienen hasta el final de su vida los problemas de las resistencias y de la experiencia. En este sentido, Deleuze y Guattari, en su "Micropolitica y segmentaridad" (DELEUZE \& GUATARI, 2000), nos ofrecen una conceptualización que podría ayudar a una lectura más integrada, que la de Foucault, y a la vez servir a un marco de interpretación de esta experiencia de lucha de clases anterior a la existencia de clases. En su particular noción del hombre como animal segmentario (que busca salir de la dicotomía entre sociedades segmentarias y sociedades centralizadas), estos autores reconocen dos grandes formas de segmentaridad que coexisten: la flexible y la dura, que también son pensables como molecular y molar al interior del problema de lo minoritario y lo mayoritario (estadístico, englobante, totalizante). Por esto plantean, alejándose de un interés exclusivo en lo minoritario, que toda política es a la vez macropolítica y micropolítica. En este texto retoman el problema de la plebe, pero bajo el concepto de "masa", así como el de las luchas de resistencia y su vinculación con el concepto de clase. Vale la pena citar en extenso los que estos autores plantean: "Las tentativas de distinguir masa y clase tienden efectivamente hacia el siguiente límite: que la noción de masa es una noción molecular, que procede por un tipo de segmentación irreductible a la segmentación molar de clase. Sin embargo, las clases están talladas en las masas, las cristalizan. $Y$ las masas no cesan de fluir, de escaparse de las clases. [...] Se dice equivocadamente (sobre todo en el marxismo) que una sociedad se define por sus contradicciones. Pero eso sólo es cierto a gran escala. Desde el punto de vista de la micropolítica, una sociedad se define por sus líneas de fuga, que son moleculares. Siempre fluye o huye algo, que escapa a las organizaciones binarias, $[\ldots]$ : todo lo que se incluye dentro de lo que se denomina 'evolución de las costumbres', los jóvenes, las mujeres, los locos, etc. [...] Como decía Gabriel Tarde, habría que saber qué campesinos, y en qué regiones del Mediodía, han empezado a negar el saludo a los propietarios de su entorno. [...] 
No obstante, lo contrario también es cierto: las fugas y los movimientos moleculares no serían nada si no volvieran a pasar por las grandes organizaciones molares, y no modificasen sus segmentos, sus distribuciones binarias de sexos, de clases, de partidos.

[...] Bajo la reproducción de las clases siempre hay un mapa variable de las masas. La política actúa por macro-decisiones y opciones binarias, intereses binarizados; pero el margen de decisión es muy pequeño. La decisión política está inmersa necesariamente en un mundo de microdeterminaciones, de atracciones y de deseos, que ella debe presentir o evaluar de otra manera [...]. Buena o mala, la política y sus juicios siempre son molares, pero es lo molecular, con sus apreciaciones, quien la "hace"' (idem, p. 215-225; grifos en el original).

No es de asombrar que revisando otros textos de esta antropología carioca y paulista en la que se etnografían experiencias vinculadas a la criminalidad los nombres de Deleuze y Guattari aparezcan con tanta o más fuerza que el de Foucault (BARBOSA, 1998; BIONDI, 2010).

\section{CONCLUSIONES}

En suma, entendemos que los análisis microfísicos de los mecanismos de control (encarnados en instituciones familiares, escolares, laborales, políticas, penales, comunicacionales etc.) y los cambios operados en sus formas resultan un contrapunto fundamental, una verdadera filigrana, pero también un complemento coherente, para los abordajes etnográficos desde abajo que apuntando a la "escala urbana" problematizan la relación entre las prácticas criminales y, al decir de Telles e Hirata, "la gestión de ilegalidades inscritas en los agenciamientos concretos de la vida cotidiana" (TELLES \&
HIRATA, 2007, p. 176-177). Y, a su vez, las reflexiones sobre lo "macro" y lo "micro" a las que esta articulación nos llevan pueden ser de mucha ayuda para captar el modo en que esas historias menores se articulan en el campo social sosteniendo ese efecto, bien real, que llamamos "cultura popular" o "de clase". Evitaríamos de este modo caer en la trampa de un concepto trascendente que nos tienta a sustancializar sujetos, pero también un giro fenomenológicoposmoderno que condena nuestro abordaje a transformarse en una mirada que desestima toda una forma de segmentación social.

Lejos de los abordajes que recortan "un espacio alienado (en el doble sentido de extraño y extranjero)", es decir, exotizado (WACQUANT, 2007, p. 67; grifos en el original), estaremos, así, ante una propuesta metodológica que intenta comprender los cambios operados en las tramas urbanas de los barrios estigmatizados al interior de un proceso conflictivo y múltiple en el que estrategias y lógicas muy diversas, locales y supralocales se ponen en juego dando lugar a nuevas figuras sociales. El requisito obligado para caminar en este sendero es afinar nuestra sensibilidad a fin de reconocer la productividad de los lazos sociales en que se define la confluencia entre las microáreas y una noción de política ampliada. Como bien descubre Zaluar en su trabajo: "Si la política es tomada en un sentido más amplio, la propia producción y socialización de reglas y valores reglamentados en las relaciones de poder y en las autoridades locales son fenómenos políticos, tanto más porque son estas reglas y estos valores los que proporcionan el 'sentido' (el bueno o el común) a través del cual los trabajadores perciben y juzgan las relaciones de poder extra locales y el Estado" (ZALUAR, 1994, p. 182; citado también por ALVITO, 2001, p. 156).

Joaquín Santiago Gómez (joaquin_s_gomez@yahoo.com.ar) é Doutorando em Antropologia na Universidade de Buenos Aires (UBA) e Professor de Antropologia Política e Jurídica na mesma universidade.

\section{REFERÊNCIAS BIBLIOGRÁFICAS}

ACOSTA, F. 2004. Os ilegalismos privilegiados. Revista Antropolítica, Niterói, n. 16, p. 6598, $1^{\circ}$ sem.

ALVITO, M. 2001. As cores de Acari. Uma favela carioca. Rio de Janeiro: Fundação Getúlio Vargas.

ANDERSON, P. 1985. Teoría, politica e historia: un debate con E. P. Thompson. Madrid: Siglo XXI. 
ARENDT, H. 1994. Sobre a violência. Rio de Janeiro: Relume Dumará.

BARBOSA, A. R. 1998. Um abraço para todos os amigos: algumas considerações sobre o tráfico de drogas no Rio de Janeiro. Niterói: UFF.

BIONDI, K. 2010. Junto e misturado: uma etnografía do PCC. São Paulo: Terceiro Nome.

COHEN, S. 1998. Visiones de control social: delitos, castigos y clasificaciones. Barcelona: Promociones y Publicaciones Universitarias.

DE GIORGI, A. 2006. El gobierno de la excedencia. Posfordismo y control de la multitud. Madrid: Traficantes de Sueños.

DELEUZE, G. \& GUATTARI, F. 2000. 1933 Micropolítica y segmentaridad. In: mil Mesetas. Capitalismo y esquizofrenia. Valencia: Pre-textos.

ELIAS, N. 1994a. A sociedade dos indivíduos. Rio de Janeiro: J. Zahar.

1994b. O processo civilizador: uma história dos costumes. Rio de Janeiro: J. Zahar.

ERIBON, D. 2004. Una moral de lo minoritario: variaciones sobre un tema de Jean Genet. Barcelona: Anagrama.

FONSECA, C. 2004. Família, fofoca e honra. Etnografia de relações de gênero e violência em grupos populares. Porto Alegre: UFRGS.

FORTANET, J. 2008. Leer a Foucault. Una crítica de la experiencia. Daímon, Murcia, n. 43, p. 15-32. Disponível em: http://digitum.um.es/ xmlui/bitstream/10201/13140/1/ Leer\%20a\%20Foucault $\% 20$ Una $\% 20$ critica $\% 20 \mathrm{de} \% 201 \mathrm{a} \% 20$ experiencia.pdf. Acesso em: 3.set.2011.

FOUCAULT, M. 1967. Historia de la locura en la época clásica. Ciudad del México: Fondo de Cultura Económica. Disponível em: http:// patriciolepe.files. wordpress.com/2007/06/ foucault-michel-historia-de-la-locura.pdf. Acesso em: 3.set.2011.

1979. Microfisica do poder. Rio de Janeiro: Graal. Disponível em: http://vsites.unb.br/fe/ tef/filoesco/foucault/microfisica.pdf. Acesso em: 4.set.2011. 1992a. Poderes y estrategias. In:

Microfísica del poder. Madrid: La piqueta.

1992b. Entrevista sobre la prisión: el libro y su método. In: Madrid: La piqueta. Microfisica del poder.

1992c. Los intelectuales y el poder. Entrevistas Michel Foucault-Gilles Deleuze. In: . Microfísica del poder. Madrid: La piqueta.

1999. Las mallas del poder. En: Estética, ética y hermenéutica. Barcelona: Paidós.

2000a. Vigilar y castigar. Ciudad de Méjico: Siglo XXI.

2000b. Defender la Sociedad. Buenos Aires: Fondo.

2000c. Historia de la sexualidad. La voluntad de saber. Ciudad de México: Siglo XXI. Disponível em: http://www. uruguaypiensa.org.uy/imgnoticias/681.pdf. Acesso em: 4.set.2011.

2001. El sujeto y el poder. In: DREYFUS, H. L. \& RABINOW, P. Michel Foucault: más allá del estructuralismo y la hermenéutica. Buenos Aires: Nueva Visión.

GINZBURG, C. 1999. El queso y los gusanos. Barcelona: Muchnik.

GUEDES, S. L. 1997. Jogo de corpo. Um estudo de construção social de trabalhadores. Niterói: UFF.

JAMES, D. 1990. Resistencia e integración: el peronismo y la clase trabajadora argentina (1947-1976). Buenos Aires: Sudamericana.

LENIN, V. I. 2001. ¿Qué Hacer? Proyecto Espartaco. Disponível em: http://www. bvsst.org.ve/documentos/pnf/que_hacer.pdf. Acesso em: 8.set.2011.

MÍGUEZ, D. 2008. Delito y cultura: los códigos de la ilegalidad en la juventud marginal urbana. Buenos Aires: Biblos.

MÍGUEZ, D. \& SEMAN, P. (eds.). 2006. Entre santos, cumbias y piquetes. Las culturas populares en la Argentina reciente. Buenos Aires: Biblos. 
PUEX, N. 2004. Eìchanges, parenteì, violence et organisation sociale d'une villa miseria $d u$ Grand Buenos Aires. Paris. Tese (Doutorado em Antropologia). Université de la Sorbonne nouvelle.

SAÍ́N, M. 2004. Política, polícia y delito. La red bonaerense. Buenos Aires: Capital Intelectual.

SIMONDON, G. 2009. La individuación a la luz de las nociones de forma e información. Buenos Aires: La Cebra.

TELLES, V. S. \& HIRATA, D. V. 2007. Cidade e práticas urbanas: nas fronteiras incertas entre o ilegal, o informal e o ilícito. Estudos Avançados, São Paulo, v. 21, n. 61, p. 173-
191. Disponível em: http://www.scielo.br/pdf/ ea/v21n61/a12v2161.pdf. Acesso em: 4.set.2011.

THOMPSON, E. P. 1989. La sociedad inglesa del siglo XVIII: ¿Lucha de clases sin clases?. In:

Tradición, revuelta y conciencia de clase. Estudios sobre la crisis de la sociedad preindustrial. Barcelona: Crítica.

WACQUANT, Loïc. 2007. Los condenados de la ciudad. Gueto, periferias y Estado. Buenos Aires: Siglo XXI.

ZALUAR, A. 1994. A máquina e a revolta. As organizações populares e o significado da pobreza. São Paulo: Brasiliense. 


\section{THE EXPERIENCE OF DELINQUENCY IN TWO ALTERNATIVE ETHNOGRAPHIC APPROACHES}

\section{Joaquin Santiago Gomez}

In this essay I present a critical review of three ethnographies dealing with the experience of delinquency in contemporary societies. As is common practice, I look at how they define their object and carry out their work, but most importantly, focus on what I understand as radically different ways of constructing the field. I look specifically at the different place that the "criminal act" has in these anthropological works, which leads me to locate Daniel Míguez' recent work in Argentina within alternative methodologies; something similar can be said regarding Alba Zaluar and Marcos Alvito's ethnographies, carried out in the Brazilian city of Rio de Janeiro. Finally, in a last section, I discuss the creative relationship - although not explicitly recognized in the ethnographies I look at that the Brazilian works may have with Michel Foucault (a relationship that is more evident in other authors, such as Michel Misse, whose work may also be included in this perspective). In this manner, I attempt to direct critical attention to approaches that, while offering valuable contributions on particular issues, remain blind to the same phenomena that conventional criminology ignores, since they also construct their field research around the notion of "delinquency".

KEYWORDS: delinquency; Ethnography; Criminology; construction; Rio de Janeiro. 
L'EXPÉRIENCE DE LA DÉLINQUANCE DANS DEUX APPROCHES ETHNOGRAPHIQUES ALTERNATIVES

\section{Joaquin Santiago Gomez}

Dans cet article, je montrerai critiquement trois éthnographies qui ont abordé l'expérience de la délinquance dans les sociétés contemporaines. Je le ferai en soulignant la façon dont on a défini son objectif et réalisé son travail, mais aussi en conduisant la discussion à ce que je comprends comme deux formes radicalement différentes de construire le domaine. Précisément, le fait de comprendre la place spéciale qui occupe « l'acte criminel» dans ces travaux anthropologiques, nous aidera à nous situer dans les directions de vérification alternatives ; d'un côté, avec le récent travail réalisé en Argentine par Daniel Míguez et, de l'autre, avec deux éthnographies brésiliennes établies à Rio de Janeiro - entre celles où nous identifions une claire continuité -, les travaux de Alba Zaluar et Marcos Alvito. Dans la dernière partie de l'article, ma préoccupation sera de signaler la relation fructueuse (et pas reconnue officiellement dans les éthnographies que nous vérifions), que cette ligne de travail développée au Brésil peut avoir avec les travaux de Michel Foucault (cette relation est plus claire chez d'autres auteurs, comme Michel Misse, dont la production pourrait aussi être incluse dans cette perspective). De cette façon, j'ai l'intention d'attirer l'attention sur les approches qui pourraient offrir des contributions précieuses aux questions abordées, mais qui restent aveugles aux mêmes phénomènes que la criminologie conventionnelle ignore, vu qu'ils partagent avec celleci, la construction d'un domaine d'étude soutenu sur la « délinquance ».

MOTS-CLÉS: la délinquance : l'ethnographie ; la criminologie ; la construction ; Rio de Janeiro. 